\title{
College Athletes and NCAA Violations
}

\author{
Jason A. Winfree
}

University of Michigan

S ports are used frequently as a window to examine society. Because of unique data sets, sports allow researchers to test human behavior, and in recent years, sports have been used to show when discrimination, collusion, and cheating are likely to occur. Cullen, Latessa, and Jonson (2012, this issue) use data on National Collegiate Athletic Association (NCAA) infractions to investigate how often and why college athletes break NCAA rules. Cullen et al. categorize these infractions as infractions while they were being recruited by the university and infractions that were committed after they enrolled in college. They find that whereas major NCAA infractions are rare, minor infractions happen somewhat frequently. Their results provide valuable insights into the causes of rule infractions, and the results may be useful in designing policies in a broader context.

The data used in the study enable the researchers to test the frequency as well as possible causes of athlete infractions. Weak evidence exists in favor of a variety of existing theories, but some consistent results are found. If athletes clearly can gain from committing an infraction, if their friends are getting away with committing infractions, and if the moral costs are perceived as being inconsequential, then athletes are more likely to break the rules. In other words, if the benefits clearly outweigh the costs, then the main barrier that stops infractions is the athlete's own moral compass. Furthermore, many athletes do not feel a moral obligation to follow all the rules, and some feel entitled to benefits that are prohibited. Therefore, athletes in large revenue-generating sports, such as football and men's basketball, commit minor infractions regularly.

A somewhat unique aspect of NCAA rules is why they exist. Even the casual observer of college sports knows that college sports have become big business and that revenues have been increasing at a rapid rate over the past couple of decades. Yet, any financial benefits to the athletes are restricted. The NCAA claims that their rules are in place to keep athletes amateurs and that these rules are in the best interest of the athletes. However, as Humphreys (2012, this issue) says, this seems peculiar because these rules prohibit monetary transfers

Direct correspondence to Jason A. Winfree, School of Kinesiology, University of Michigan, Observatory Lodge, 1402 Washington Heights, Ann Arbor, MI 48109 (e-mail: jwinfree@umich.edu). 
from universities to athletes explicitly, and universities are the ones in charge of the NCAA. I hope that no governing bodies are looking out for my best interest in the same manner as the NCAA.

So naturally, many of the athletes feel a sense of entitlement. Consequently, it does not take long for some college athletes to perceive themselves to be an integral part of a large and growing business, where others receive nearly all the pecuniary rewards. As Piquero (2012, this issue) notes, in other contexts, entitlement has proved to be important in understanding determinants of crime. Clearly, if the student athletes feel entitled to a piece of the financial pie, the moral cost of breaking the rules is mitigated.

This context creates an interesting dilemma. Many economists would argue that some NCAA rules are unnecessary in terms of social welfare and serve only to benefit athletic departments that behave like a cartel or monopsony at the expense of athletes. After all, if universities cannot pay athletes, then they will pay the people or facilities that recruit the athletes, thereby increasing the value of coaches and amenities. Obviously, some would disagree with the economists' assessment, but surely many of the athletes would favor the economists' view. Nonetheless, rules are rules. So although some observers might question the objectives of the policy makers, surely the policy makers want compliance of the rules. This research seems to indicate that athletes often are in violation of minor infractions and rarely are caught for these minor infractions. Also, compliance is largely a function of the athlete's perceptions of the moral authority of the rules, which leads to some interesting questions. How bad is it if athletes break rules that they, and many others, perceive as unfair? Is it more effective to increase punishments or to increase surveillance? Or should we try to convince people of the morality of the rules? Does this mean that rule makers should not or cannot effectively create rules that are not consistent with people's morals? Do rules that are not easily enforced only punish those who are willing to follow the rules? Perhaps these questions may be an interesting line of future research.

It seems that since the study's survey was conducted, the NCAA has gradually loosened up some of its restrictions, giving athletes a slightly bigger share of the pie. Maybe the NCAA has eliminated some rules because many minor violations were occurring with a high frequency anyway, and perhaps minor violations are a gateway to major violations. On the other hand, the NCAA's response could be the result of public pressure to treat athletes better. As Humphreys (2012) notes, the NCAA has a sizeable financial incentive to keep its monopsony intact; perhaps giving some small concessions is a way to preserve their monopsony power.

But this loosening of policies is not what Cullen et al. (2012) suggest. They also are skeptical of increasing punishments to increase compliance. Instead, they explicitly favor intervention with at-risk athletes and athlete education of the rules. Of course, it is possible that compliance with minor infractions is not the main objective of the NCAA, but whatever the case, this study provides an interesting context to these NCAA rule changes. 
To what extent the results of Cullen et al. (2012) are generalizable to other segments of society is unclear, although Piquero (2012) indicates that the results are more or less in line with research in other contexts. Hopefully, future research will show us exactly how unique college sports is as a context for breaking rules. Regardless, this study does give us interesting insight into who breaks rules and why.

\section{References}

Cullen, Francis T., Edward J. Latessa, and Cheryl Lero Jonson. 2012. Assessing the extent and sources of NCAA rule infractions: A national self-report study of student-athletes. Criminology \& Public Policy, 11: 667-706.

Humphreys, Brad R. 2012. NCAA rule infractions: An economic perspective. Criminology \& Public Policy, 11: 707-712.

Piquero, Alex R. 2012. Assessing the extent and sources of NCAA rule infractions. Criminology \& Public Policy, 11: 713-722.

Jason A. Winfree is an associate professor in the Department of Sport Management at the University of Michigan. Most of his research is in the area of sports economics and focuses on issues such as demand for sports, league policies, performance enhancing drugs in sports, and antitrust issues in sports. He recently co-authored a textbook, Sports Finance and Management: Real Estate, Entertainment and the Remaking of the Business (2011). 